\section{SAFTY OF CONTRAST}

\section{- Contrast media and safety:}

Contrast agents in medicine are chemical materials used to improve tissue and fluid contrast in the body during medical imaging. It is mainly used in improving the visibility of blood vessels and the gastrointestinal tract. Some types of contrast materials are used in a medical imaging examination and can be classified according to the imaging technique used. The first contract agent (Gadolinium) dates back to 1988 which is called gadopentetate dimeglumine (Magnevist ${ }^{\circledR}$ ) and was allocated for Magnetic Resonance Imaging (MRI).

\section{Objectives}

1. What is the Gadolinium?

2. What is the safest Gadolinium?

3. What is the chemical composition of Gadolinium?

4. How to deal with NFS patients?

\section{Methodology}

This is a review of the history of contrast media in terms of the safest contrast media, and how to deal with NFS patient.

\section{Chemistry}

The gadolinium ion is useful as an MRI contrast agent because it has seven unpaired electrons, which is the greatest number of unpaired electron spins possible for an atom.

Gadolinium molecules shorten the spin-lattice relaxation time (T1) of voxels in which they are present. As a result, on T1-weighted images they have a brighter signal.
1. Safest(cyclical structure)

- Dotarem, Gadovist, ProHance.

2. Intermediate safety(ionic liner structure)

- Magenvist, MultiHance, Primovist, Vasovist.

3. Lowest safety(liner non-ionic structure)

- Ominsacn, OptiMark.

\section{- Tips and Tricks:}

- eGFR $30-60 \mathrm{ml} / \mathrm{min} / 1.73 \mathrm{~m}^{2}$ :choose safety contrast agent, use only with caution.

- $\mathrm{eGFR}<30-60 \mathrm{ml} / \mathrm{min} / 1.73 \mathrm{~m}^{2}$ :liner structured contrast agents contraindicated.

- In patient with severe renal failure: consider hemodialysis within 2 hours after contrast agent administration-not proven to prevent NFS.

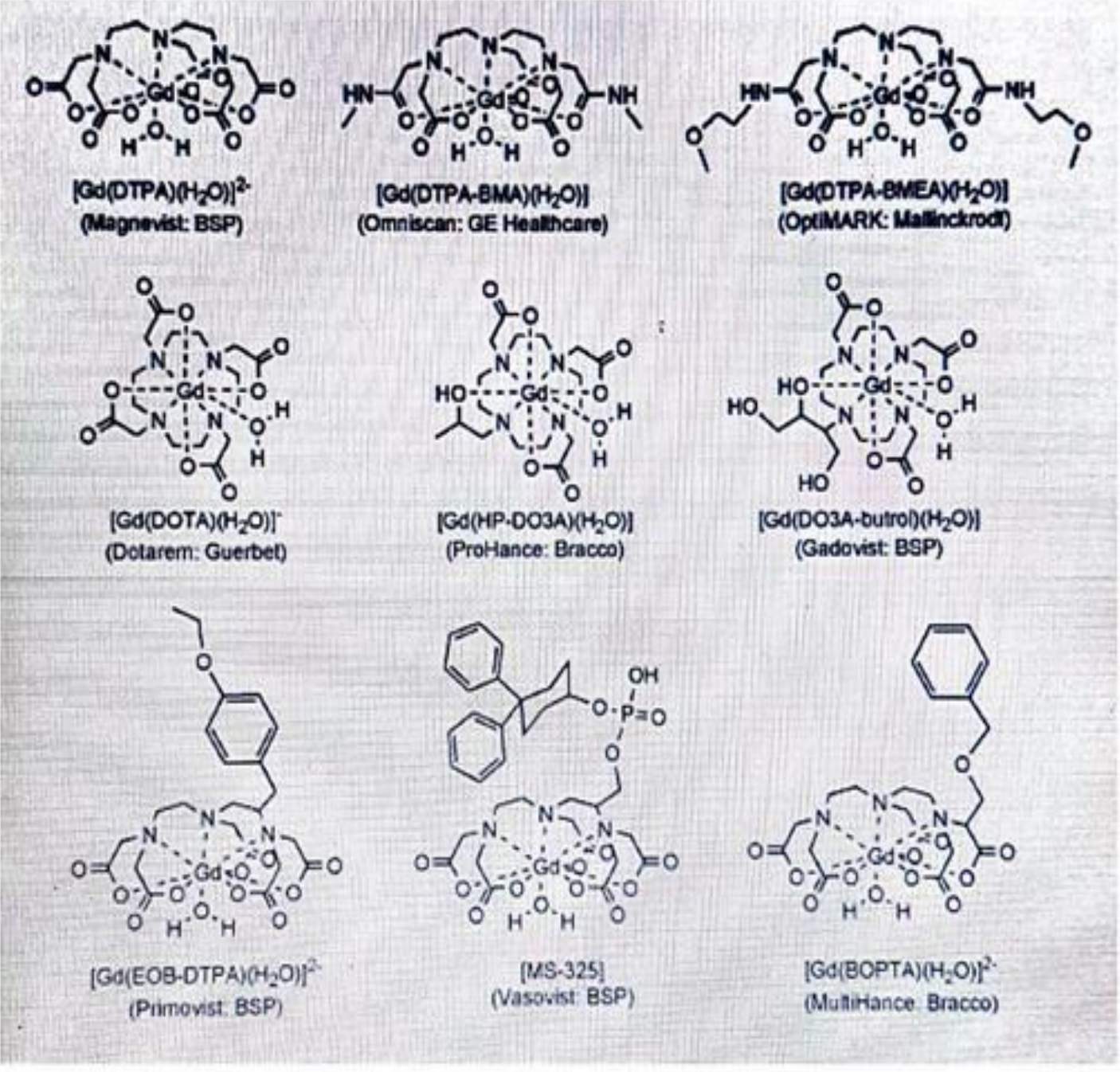

\section{Mechanism of Enhancement}

Tissue that demonstrates enhancement following administration of gadolinium-containing IV contrast does so because of a combination of the following two mechanisms:

- intravascular enhancement

- interstitial enhancement

Which one of these dominates depends on the characteristics of the tissue.

\section{Conclusion}

- The cyclical structure compounds are the most stable chemically, so they are the most safe for patients, while the linear ionic compounds are the most unstable and not the least safe for patients.

- The domain of contrast materials in MRI has expanded beyond expectations since the approval of the first MRI contrast agent, gadopentetate dimeglumine, in the last three decades, and it continues to evolve. Today, CE-MRI is a valuable and established modality for multiple indications in many body regions. New techniques are bringing exciting novel possibilities for MRI, alongside associated clinical challenges.

\section{References}

Alshowiman, S. S., Alswailem, A. K., Almohizy, O. A., Alfawaz, A. A., \& Alshaikh, A. A. I. (2018). MRI Contrast Agents: Developments, Challenges, and Future Trends. International Journal of Pharmaceutical Science Invention, 7(4), 11-22.

Behzadi, A. H., Zhao, Y., Farooq, Z., \& Prince, M. R. (2018) Immediate allergic reactions to gadolinium-based contrast agents: a systematic review and metaanalysis. Radiology, 286(2), 471-482.

Fraum, T. J., Ludwig, D. R., Bashir, M. R., \& Fowler, K. J. (2017). Gadolinium-based contrast agents: A comprehensive risk assessment. Journal of Magnetic Resonance Imaging, 46(2), 338-353. 